\title{
Preface of the "4th Symposium on Modelling and Simulation in Computer Sciences and Engineering"
}

Cite as: AIP Conference Proceedings 2116, 250001 (2019); https://doi.org/10.1063/1.5114241

Published Online: 24 July 2019

Francisco Miranda, Carlos Abreu, and Daniel Miranda

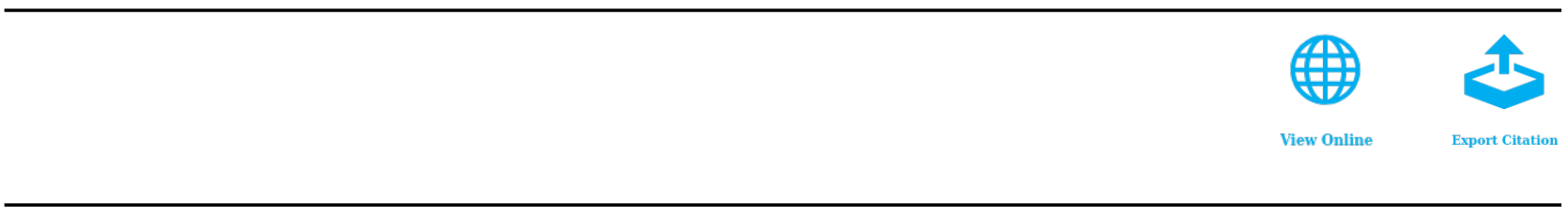

\section{Conference Proceedings}

Get $30 \%$ off all print proceedings!

\section{Enter Promotion Code PDF30 at checkout}

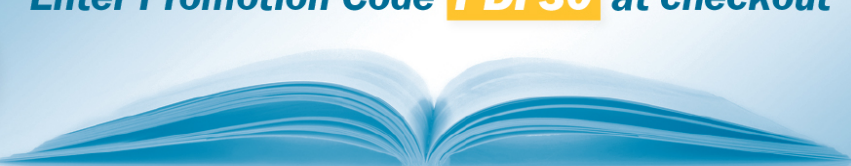




\title{
Preface of the "4th Symposium on Modelling and Simulation in Computer Sciences and Engineering"
}

\author{
Francisco Miranda $^{1,2, a)}$, Carlos Abreu $^{2,3, b)}$ and Daniel Miranda ${ }^{4, c)}$ \\ ${ }^{1}$ CIDMA, Universidade de Aveiro, Aveiro, Portugal \\ ${ }^{2}$ Instituto Politécnico de Viana do Castelo, Viana do Castelo, Portugal \\ ${ }^{3}$ CMEMS-UMINHO, Universidade do Minho, Braga, Portugal \\ ${ }^{4} 2$ Ai- Polytechnic Institute of Cávado and Ave, Barcelos, Portugal \\ a)Corresponding author: fmiranda@estg.ipvc.pt

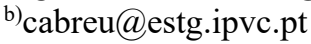 \\ c)damiranda@ipca.pt
}

The 4th Symposium on Modelling and Simulation in Computer Sciences and Engineering was held in the 16th International Conference of Numerical Analysis and Applied Mathematics (ICNAAM 2018), Rhodes, Greece, 13-18 September 2018.

Modelling and simulation, applied to computer science and engineering, is an exciting research area that uses the computational power of modern information processing systems to improve our understanding about the real world. Computer simulations and graphical visualizations play a fundamental role developing mathematical models to examine problems that would be too expensive, too much dangerous, or even impossible to study by direct experimentation. Moreover, virtual prototyping, using modelling and simulating software, is a keystone process to bring down the overall cost of designing and developing novel products. Indeed, the rising number of organisations using these technologies has led to a dramatic increase in demand for better research and skilled professionals in this research area.

As in the last symposia, that were great successes in ICNAAM 2014, 2015 and 2016, the aim of this 4th symposium was to provide research regarding modelling and simulation techniques applied to the physical sciences and engineering, where the purpose of the symposium activities was to discuss theoretical studies and experimental results with interest in several topics like modelling in engineering sciences and technology, dynamical systems models and methods, computational methods in engineering, computer science modelling and simulation, computer networks modelling, optimization, simulation and control theory, stochastic optimization, numerical methods and simulation, systems modelling, computational mathematics, analysis of mathematical models, algorithms and data structures, software design, control and systems engineering.

\section{ACKNOWLEDGMENTS}

The organisers of the symposium thank to all the reviewers and the technical program committee that assisted them to strengthen this important event. They also thank to the organisers of the International Conference of Numerical Analysis and Applied Mathematics for allowing to realize this symposium.

Technical Program Committee: António Abel Henriques, António Curado, António Mário L. F. Almeida, Bibudhendu Pati, Chhabi Rani Panigrahi, Daniel Filipe Albuquerque, Giovanni Pau, Helena Sofia Rodrigues, Hugo Rodrigues, James M. Raude, João F. Nunes, João Manuel R. S. Tavares, Manuel Rui Alves, Meera Viswavandya, Paula Alexandra Rego, Paulo Caldas, Pedro Dinho da Silva, Pedro Dinis Gaspar, Pedro Pinto, Pijush Samui, Reza Gharoie Ahangar, Roohollah Kalatehjari, Rui Carneiro, Sónia Dias, Tawanda Mushiri, Tiago Pedrosa, Torsten Hermanns, Vai Kuong Sin, Yildirim Dalkiliç. 
The symposium was supported by Portuguese funds through the CIDMA - Center for Research and Development in Mathematics and Applications, and the Portuguese Foundation for Science and Technology ("FCT - Fundação para a Ciência e a Tecnologia"), within project UID/MAT/04106/2013.

\section{Francisco Miranda}

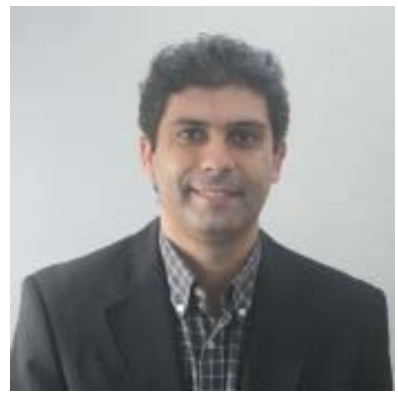

Francisco Miranda was born on April 1, 1975 in Viana do Castelo, Portugal. He graduated in Mathematics from University of Coimbra in 1999. Having done research on Control Theory he earned his MSc and PhD degrees in Applied Mathematics from University of Porto in 2003 and 2008, respectively. His research interests focus on stabilization and observability of control systems, optimal control, guidance control, numerical methods of stabilizer construction, time scales, Biomathematics and mathematical modelling in healthcare. Currently, he is Professor of Mathematics Department at Polytechnic Institute of Viana do Castelo, Portugal. He is also a researcher at Center for Research and Development in Mathematics and Applications, University of Aveiro, Portugal, and a research collaborator at Research Unit in Materials, Energy and Environment for Sustainability of Polytechnic Institute of Viana do Castelo, Portugal.

\section{Carlos Abreu}

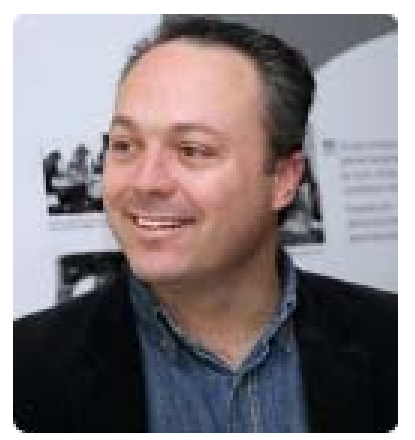

Carlos Abreu was born on September 8, 1976 in Esposende, Braga, Portugal. He graduated in Electronics and Telecommunications from University of Aveiro in 2005. Having done research on Instrumentation, Signal and Medical Image he earned his MSc degree in Biomedical Engineering in 2008. In 2014 he received his $\mathrm{PhD}$ in Biomedical Engineering from the University of Minho, Portugal. His research interests focus on Biomedical Cyber-Physical Systems and Biomedical Data Science. Currently, he is working as Assistant Professor of Engineering at the Polytechnic Institute of Viana do Castelo (IPVC), Portugal.

\section{Daniel Miranda}

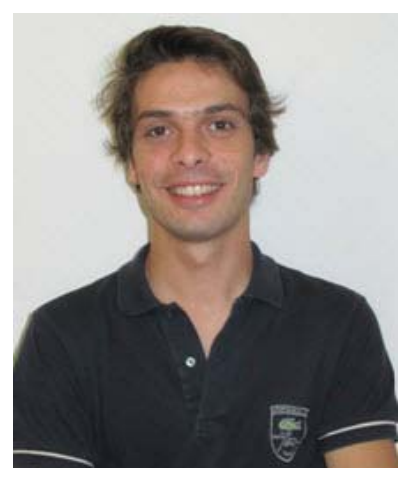

Daniel Miranda was born on May 18, 1981 in Viana do Castelo, Portugal. He graduated in Physics and Chemistry from University of Minho in 2005. In 2008, he obtained the MSc degree in Physics from the University of Minho. During his MSc thesis, he worked on Materials, Nanoscience, Nanotechnology, Processing and characterization on poly(vinylidene fluoride) doped with nano-silver particles. In 2017 he earned his PhD in Physics from the University of Minho, Portugal, with thesis theme: "Optimizing performance of rechargeable lithium-ion batteries through computer simulations". Currently, he is Assistant Professor at School of Technology, Polytechnic Institute of Cávado and Ave, Portugal, integrated member/researcher of 2Ai Laboratory at IPCA and researcher of Electroactive Smart Materials Research Group at University of Minho. He is currently focused on the development of theoretical models of lithium ion batteries through computational simulation (Finite Elements Method) and computational simulation and modeling applied in energy, energy systems, storage energy applications. Also, his current research interests focus on development of theoretical models and computational simulation applied in different areas, such as: supercapacitors, materials science (materials for energy applications: electrodes and battery separators), industrial applications and technologies (robotic, sensors, mechanics devices, thermodynamic systems or air conditioning systems, fluidic and microfluidic systems, electrical and electronic devices), health technologies (diagnostic systems), simulation systems and serious games. 